\title{
REVISTAS CIENTÍFICAS DA BIBLIOTECONOMIA E CIÊNCIA DA INFORMAÇÃO: UMA ANÁLISE DOS PLUGINS OPEN J OURNAL SYSTEM (OJ S) E CRITÉRIOS SCIELO
}

\author{
Josiane Ribeiro Prestes \\ Bacharel no Curso de Biblioteconomia na Universidade \\ Federal do Rio Grande (FURG). \\ josiane.caic@gmail.com \\ https://orcid.org/0000-0002-6371-0224
}

\author{
Simone Firme Machado \\ Doutoranda no Programa de Pós-Graduação em \\ Educação em Ciências (PPGEC) na Universidade \\ Federal do Rio Grande (FURG). \\ simonemachadofirme@gmail.com \\ https://0000-0002-0409-1857 \\ Angélica C. D. Miranda \\ Professora no Programa de Pós-Graduação Educação \\ em Ciências e no Programa de Pós-Graduação em \\ Administração na Universidade Federal do \\ Rio Grande (FURG). \\ angelicacdm@gmail.com \\ https://orcid.org/0000-0003-3624-4616
}

\begin{abstract}
RESUMO
Apresenta estudo sobre 21 revistas científicas de Biblioteconomia e Ciência da Informação, a partir do estrato Qualis A1, A2 e B1, com base nos critérios SciELO e na identificação dos plugins Open Journal Systems (OJS) habilitados. Quanto aos métodos usados, a pesquisa de caráter exploratório e descritivo, usou-se 2 instrumentos para coleta de dados. Constatou-se que, das 21 revistas, 10 não têm a totalidade de plugins habilitados. Duas revistas não foram analisadas em decorrência de um link quebrado. Quanto aos critérios Qualis, é possível afirmar que algumas revistas, com estratos significativos, apresentaram inflexibilidade com resultados não favoráveis, os quais trazem uma reflexão: "até que ponto esses critérios influenciam na mudança de estrato, todos detalhados nas considerações da presente pesquisa?".
\end{abstract}

Palavras-chave: Revistas científicas. Critérios de qualidade. Plugins OJS. Comunidade científica.

\section{SCIENTIFIC JOURNALS OF LIBRARY AND INFORMATION SCIENCES: AN ANALYSIS OF OPEN JOURNAL SYSTEM (OJS) PLUGINS AND SCIELO CRITERIA}

\begin{abstract}
A study on 21 scientific journals of Library and Information Sciences is presented, base dont he Qualis strata A1, A2 and B1, according to the SciELO criteria and on the identification of enabled Open Journal Systems (OJS) plugins. As for the methods used in this research of exploratory and descriptive character, 2 instruments were used for data collection. It was found that 10 of the 21 magazines studied do not have all plugins enabled. Two magazines were not analyzed dueto broken links. As for the Qualis criteria, it is possible to state that some magazines, of high stratum, presented in flexibility with unfavorable results, which brings a reflection: "to what extent do these criteria, detailed in the considerations of this research, influence the change of stratum?"
\end{abstract}

Keywords: Scientific journals. Quality criteria. OJS plugins. Scientific community.

Recebido em: 21/04/2020

Aceito em: 20/08/2020

Publicado em: 11/09/2020

\section{INTRODUÇÃO}

Ao longo do tempo, houve uma mudança quanto ao suporte da informação, bem como ao público alvo e à sua distribuição. Os avanços tecnológicos trouxeram benefícios e vantagens quanto ao acesso. O movimento, em prol do acesso aberto, permitiu 
o compartilhamento à comunidade, acesso às informações revisadas por pares, além de proporcionar novos estudos, teorias e pesquisas.

Segundo Le Coadic (1996, p. 27),

A informação é o sangue da ciência. Sem informação, a ciência não pode se desenvolver e viver. Com a ausência da informação, a pesquisa seria inútil e não existiria o conhecimento. Passado mais de vinte anos, a afirmação ainda é válida.

A importância da informação na comunidade científica é complacente, a partir do momento em que atribui o valor na sua utilidade a filtragem na coleta desta informação para utilizar, fielmente, ao seu estudo. Desse modo, um pesquisador busca fontes seguras para realização da sua investigação, considerando o seu armazenamento. Por este motivo, o tratamento da informação é necessário para separar o que realmente é valido do que não.

Os processos editoriais foram facilitados com o uso da Plataforma OJS. Diante do seu uso, surgiram as seguintes dúvidas: a Ciência da informação, como área que atua com a divulgação e comunicação científica, utiliza-se dos plugins da ferramenta citada, para maximizar o acesso? Como as revistas da Ciência da Informação administram os processos de qualificação extrínseco e intrínseco? Nesse sentido, este estudo buscou abordar a importância do processo de qualificação das revistas científicas da Biblioteconomia e da Ciência de informação.

\section{REVISTAS CIENTÍFICAS}

As revistas científicas, também conhecidas como periódicos científicos, correspondem aos meios de comunicação. Sejam no formato impresso ou digital, propiciam acesso à informação,produzida por pesquisadores.

De acordo com Bandeira e Freire (2017, p. 58):

As tecnologias de informação contribuem para que a comunicação científica se efetive de maneira dinâmica, promovendo a melhor interação entre editores, leitores, autores e seus pares. A editoração científica, que anteriormente dependia do método manual de demandava maior tempo, verba e muitas vezes limitava-se a espaços, como região ou país, ganham novos espaços (virtuais) na contemporaneidade com a editoração eletrônica somada a iniciativa do acesso aberto. 
O acesso aberto proporcionou acessibilidade ao conhecimento produzido, liberdade para proporcionar pesquisas, descobertas, saberes e conhecimentos singulares, por meio dos artigos publicados.

Segundo Messias (2005, p. 67):

[...] a Ciência da Informação é uma área interdisciplinar orientada à prática e a pesquisa, com uma tendência ao estudo humano e social. A informação de que se ocupa não mais se restringe às informações científicas e tecnológicas, mas a de qualquer natureza gerada pelo homem.

Por ser uma área interdisciplinar, o profissional bibliotecário atua em diversas funções, atendendo a sua comunidade, com vistas a mediar a informação. Por esse viés, afirma-se que os periódicos tornaram-se imprescindíveis para acomunicação científica e para sua divulgação.

Bandeira e Freire (2017, p. 59) afirmam que:

O periódico científico é o resultado de um trabalho coletivo e os principais atores envolvidos no processo de publicação desse canal de comunicação da ciência são os autores, os editores e os avaliadores. Os autores habitualmente são pesquisadores que relatam em um manuscrito os resultados de suas respectivas pesquisas.

São notáveis o avanço da forte tendência ao crescimento de produtividade e a visibilidade nos periódicos em Ciência da Informação. Com o auxílio da tecnologia, as revistas têm buscado a qualificação, por meio de critérios de qualidade, indexadores e atualizações na identidade visual, que são os responsáveis pela melhoria na padronização da revista. É valido ressaltar que,conforme a área de conhecimento, há uma orientação quanto à padronização e às políticas estabelecidas.

A acessibilidade, em menor tempo ao conteúdo, é a prática mais instantânea atualmente. O formato impresso, conhecido há bastante tempo, desde a época do papiro, passou por transformações no material utilizado, mas mantendo as diretrizes estabelecidas, com informações da edição publicada e, até hoje, é o formato mais trabalhado. O formato eletrônico foi criado com o objetivo de facilitar o acesso, diminuir o fluxo de armazenamento físico, mas, essencialmente, direcionado à democratização do acesso. A migração para o formato digital diminui barreiras e aumenta o alcance de um periódico.

Diante disto, a comunidade científica aborda e reitera como fundamental a discussão sobre questões éticas para a produção e publicação científica. 


\subsection{Committee on Publication Ethics - COPE}

A Committee on Publication Ethics (COPE) é uma plataforma que, desde 1997, dá suporte às questões de má conduta científica, na publicação. Auxilia editores, equipes editoriais, leitores e afins, com diretrizes quanto ao fluxo editorial, questões que correspondem à ética e às boas práticas, na publicação. Segundo Coeli Lima, Carvalho (2018, p. 1):

A afiliação ao COPE representa um passo à frente em nossa política editorial, sinalizando para a comunidade de leitores, revisores e autores de CSP a nossa estrita adesão às recomendações de boas práticas editoriais. Entretanto, entendemos que nosso papel na promoção da integridade em pesquisa deva ir além.

A COPE fornece aos membros análises no periódico, quanto às diretrizes presentes na integra, assim resultando em orientações que proporcionam maior qualificação. Porém, com todo esse suporte, cabe a responsabilidade desses editores e afins, bem como a conscientização na conduta de ética na publicação.

Figura 1 - Página inicial COPE

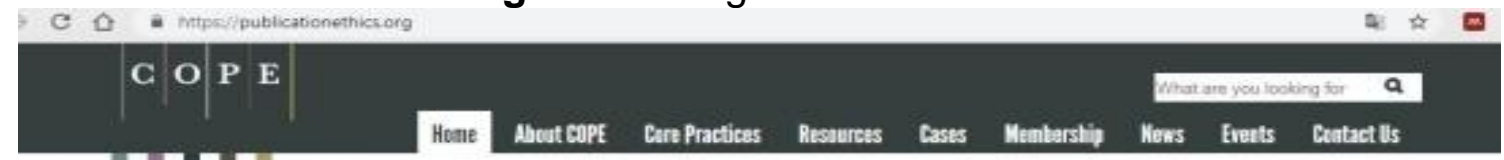

\section{Promoting integrity in research and its publication}

COPE provedes kaderstip on thinkeng on pubication ethics, praccical resources to ecoucate

and sopport members, and otters a protessional voke in currem debares.

Beas moce. abcut coef.

\section{Need help with}

\section{an issue?}

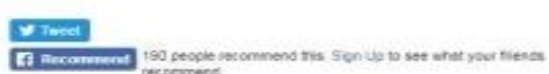

\section{Latest from COPE}

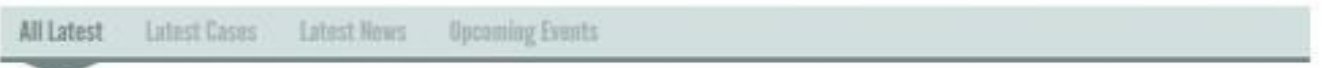

Fonte: https://publicationethics.org



As revistas brasileiras estão conhecendo e fazendo uso de diretrizes para compor as suas demais políticas. Conforme a figura 1, o COPE disponibiliza, na integra, materiais relevantes à tomada de decisões, como um fluxograma de como agir diante da má conduta, de documentos para orientar seu autor e demais envolvidos no processo editorial. 
Nota-se numa lacuna no que diz respeito à definição de ética, por existir uma diversidade de materiais, as revistas seguem caminhos diferentes. $\mathrm{Na}$ atualidade com questões de internacionalização, o recomendável é seguir o padrão internacional. Desta forma, os periódicos passam a trilhar um caminho, sem volta, na busca da qualidade, ou seja, não basta apenas existir, é necessário atentar aos padrões existentes que permeiam a transparência do conhecimento produzido.

\subsection{Qualis}

A classificação é disponibilizada na Plataforma Sucupira, por cada área de conhecimento. São representadas, por letra e números (A1, A2, B1, B2, B3, B4 e C), e os mesmos estratos são agrupados, nos respectivos conjuntos, de acordo com a classificação dos periódicos.

Pascutti (2016, p. 2) expõe que a entrada de periódicos para o Qualis dá-se anualmente, a partir dos relatórios feitos pela coordenação de Programas de Pós-Graduação, reconhecidos pela CAPES na Plataforma Sucupira. Por este motivo, as revistas precisam estar sempre a se reconstruir, de modo a atender aos critérios de avaliação da Pós-Graduação. Trabalham para obter visibilidade e prestígio, por meio do seu conteúdo. Para isso, o cuidado em habilitar plugins no OJS, cadastro/indexação em diretórios, catálogos e bases nacionais e internacionais é imprescindível. Entre estes, destaca-se, como exemplos: o Diretório de Revistas de Acesso Aberto (DOAJ), o Google Scholar, Sistema Regional de Información en Línea para Revistas Científicas de América Latina (Latindex), a Rede Iberoamericana de Inovação e Conhecimento Científico (REDBIB), CAPES, entre outras ferramentas disponíveis na rede mundial de computadores.

Pinheiro, Brascher, Burnier, (2005. p. 26) afirmam:

A existência, sobrevivência e consolidação de um periódico depende da produção científica no campo do conhecimento que cobre, portanto, de pesquisas e de cursos de pós-graduação, geradores do conhecimento, dos quais se originam os artigos científicos, matéria essencial de um periódico e sua característica principal.

Por este viés, compreende-se que os processos foram otimizados com o apoio da tecnologia, bem como a facilidade para buscar um periódico para publicar. Conforme os autores, os cursos de pós-graduação, que são produtores de conhecimento, 
foram diretamente beneficiados, visto que podem pesquisar por revistas científicas disponíveis dentro de uma determinada área. Pascutti (2016, p. 47) fala que "a classificação Qualis é um processo técnico e político", por isso, conforme as informações disponibilizadas à comunidade científica, a revista poderá ser melhor classificada. Ainda para Pascuti, os critérios que devem estar claros não são somente técnicos, de modo a atender à lei da transparência. Se a tecnologia facilitou a multiplicação das revistas, também permitiu aos cidadãos analisarem as exigências de cada um.

\subsection{Critérios de qualidade}

Existem diversos modelos de ferramentas que as revistas utilizam para uniformizar, de acordo com determinadas regras. Seu conteúdo extrínseco é avaliado, desde o comitê/conselho editorial, as bases/catálogos/diretórios, em que está indexada/cadastrada, tendo como foco suas publicações. Como um todo, deve-se preencher os quesitos de organização a qualidade, dando prioridade ao conteúdo científico.

Corrêa e Miranda (2016, p. 57) consideram que:

É nesse sentido que os critérios de qualidade em periódicos científicos online tramitam: quando contemplados, contribuem para o aumento da qualidade, disponibilidade, influência e impacto dos periódicos, objetivam também a profissionalização e a ampliação da visibilidade dessas publicações.

A qualidade dos artigos remete, diretamente,à avaliação por pares, que é uma das etapas mais importantes no processo editorial. A ausência de avaliação, por pares, causa impactos na avaliação, refletindo diretamente no Qualis. Além disso, o fluxo de recebimento de artigos também sofre, em virtude de os autores escolherem as revistas com maior notoriedade a citação.

\subsection{Plugins no sistema Open J ournal Systems - 0J S}

OJS é uma plataforma que agrupa revistas científicas e facilita os processos editoriais, bem como sua divulgação no meio digital. Possui muitas funções, dentre elas, destacam-se os plugins, que de acordo IBICT (2013, p. 79) os "Plugins do Sistema 
permitem expandir sua funcionalidade, além de aceitação de código de terceiros sem alterar o código fonte". É, ainda, uma ferramenta que aperfeiçoa a revista, a partir dos plugins habilitados. Contribui com os critérios de qualidade, por expor a descrição e metadados dos artigos, além de disseminar a produção intelectual,colaborando com a transparência do periódico. Por fim, os plugins podem auxiliar, desde os editores até os leitores, pois permitem a customização do periódico.

\subsubsection{Ferramentas de leitura}

Ferramentas de leitura são um conjunto de interfaces consideradas como plugins, que contribuem para revistas de forma mais específica. O diferencial está na apresentação, onde aparecem com vários itens nas laterais e horizontais da página, com a descrição das informações. Possibilitam, ainda,mais clareza e entendimento às questões, que facilitam e influenciam o acesso ao artigo,por meio da estruturação do periódico.

Quadro 1 - Ferramenta de leitura e seus tipos

\begin{tabular}{|l|l|}
\hline 1) Citação do artigo; & A frequênciacom que o artigo é citado \\
\hline 2) Exibir metadados; (Ferramenta de leitura) & Descrição do conteúdo \\
\hline 3) Enviar artigo via e-mail; & Plugins habilitados para envio direto aos leitores cadastrados \\
\hline 4) Enviar comentário; & Usuários cadastrados podem contribuir com ponto de vista \\
\hline 5) Imprimir artigo; & Impressão direta do conteúdo \\
\hline 6) Métricas do artigo. & As estatísticas mensais e anuais de acesso \\
\hline
\end{tabular}

Fonte: dados da pesquisa

O quadro 1 mostra os tipos de ferramentas existentes e o que cada uma representa. São funcionalidades específicas, que ocasionam a utilização de parte das ferramentas para contribuir na análise deste estudo.

\section{PROCEDIMENTOS METODOLÓGICOS}

Prodanov (2013, p. 14) explica que a Metodologia é compreendida como uma disciplina que consiste em estudar, compreender e avaliar os vários métodos disponíveis para a realização de uma pesquisa acadêmica.

Trata-se de um estudo com característica descritiva, que, segundo Gil (2002, p. 42), é "a descrição das características de determinada população ou fenômeno ou, então, o estabelecimento de relações entre variáveis", com caráter exploratório. De acordo com Prodanov (2013, p. 51), 
Pesquisa exploratória: quando a pesquisa se encontra na fase preliminar, tem como finalidade proporcionar mais informações sobre o assunto que vamos investigar, possibilitando sua definição e seu delineamento, isto é, facilitar a delimitação do tema da pesquisa; orientar a fixação dos objetivos e a formulação das hipóteses ou descobrir um novo tipo de enfoque para o assunto.

O universo da pesquisa consiste nas revistas cientificas de Biblioteconomia e $\mathrm{Cl}$ de estrato Qualis A1, A2 e B1. Em vista disso, este estudo almeja proporcionar respostas, através da análise nos plugins no Open Journal System e diretrizes SciELO.

A coleta de dados baseou-se na seleção das revistas, conforme Qualis A1, A2 e B1.

\begin{tabular}{|c|c|c|}
\hline Revistas & Qualis & Endereco eletrônico \\
\hline $\begin{array}{l}\text { 1. Informação \& Sociedade: } \\
\text { Estudos (I\&S) }\end{array}$ & A1 & http://periodicos.ufpb.br/ojs2/index.php/ies \\
\hline $\begin{array}{l}\text { 2. Perspectivas em Ciência da } \\
\text { Informação }\end{array}$ & A1 & http://portaldeperiodicos.eci.ufmg.br/index.php/pci \\
\hline 3. Transinformação & A1 & http://periodicos.puccampinas.edu.br/seer/index.php/transinfo \\
\hline 4. Encontros Bibli & A2 & https://periodicos.ufsc.br/index.php/eb \\
\hline 5. Informação \& Informação & A2 & http://www.uel.br/revistas/uel/index.php/informacao \\
\hline $\begin{array}{l}\text { 6. Revista Interamericana de } \\
\text { Bibliotecología }\end{array}$ & $\mathrm{A} 2$ & http://aprendeenlinea.udea.edu.co/revistas/index.php/RIB \\
\hline 7. Ágora (Florianópolis) & B1 & https://agora.emnuvens.com.br/ra \\
\hline 8. Biblionline & B1 & http://periodicos.ufpb.br/ojs2/index.php/biblio \\
\hline $\begin{array}{l}\text { 9. Brazilian Journal of } \\
\text { Information Science }\end{array}$ & B1 & http://www2.marilia.unesp.br/revistas/index.php/bjis/index \\
\hline $\begin{array}{l}\text { 10. BrazilianJournalism } \\
\text { Research (BJR) }\end{array}$ & B1 & https://bjr.sbpjor.org.br/bjr \\
\hline 11. Ciência da informação & B1 & http://revista.ibict.br/ciinf \\
\hline 12. Em questão & B1 & http://seer.ufrgs.br/EmQuestao \\
\hline 13. InCID & B1 & https://www.revistas.usp.br/incid/ \\
\hline 14. Intexto & B1 & http://www.seer.ufrgs.br/intexto \\
\hline $\begin{array}{l}\text { 15. Perspectivas em Gestão \& } \\
\text { Conhecimento }\end{array}$ & B1 & http://periodicos.ufpb.br/ojs/index.php/pgc \\
\hline $\begin{array}{l}\text { 16. Pesquisa Brasileira em Ciência } \\
\text { da Informação e Biblioteconomia }\end{array}$ & B1 & http://periodicos.ufpb.br/ojs/index.php/pbcib \\
\hline 17. Ponto de Acesso & B1 & http://www.portalseer.ufba.br/index.php/revistaici \\
\hline $\begin{array}{l}\text { 18. RECIIS: Comunicação, } \\
\text { Informação e Inovação em Saúde }\end{array}$ & B1 & https://www.reciis.icict.fiocruz.br/index.php/reciis \\
\hline $\begin{array}{l}\text { 19. RBBD Revista Brasileira de } \\
\text { Biblioteconomia e Documentação }\end{array}$ & B1 & https://rbbd.febab.org.br/rbbd \\
\hline $\begin{array}{l}\text { 20. Revista Digital de } \\
\text { Biblioteconomia e Ciência da } \\
\text { Informação }\end{array}$ & B1 & https://periodicos.sbu.unicamp.br/ojs/index.php/rdbci \\
\hline $\begin{array}{l}\text { 21.Tendências da Pesquisa } \\
\text { Brasileira em Ciência da } \\
\text { Informação }\end{array}$ & B1 & http://inseer.ibict.br/ancib/index.php/tpbci \\
\hline
\end{tabular}

Fonte: Dados da pesquisa 
As ferramentas utilizadas na pesquisa foram 16 diretrizes da SciELO (Quadro 3), escolhidas de acordo com as necessidades aplicadas, nas 21 revistas selecionadas com estrato Qualis A1, A2 e B1. Vale observar que foi aplicada parte das diretrizes para avaliação, pois não teve necessidade de sua utilização por completo, e os 6 plugins habilitados no OJS, que são as ferramentas de leitura (Quadro 1), foram ressaltados para elencar questionamentos de contribuição que o sistema oferece.

Quadro 3 - Diretrizes SciELO

\begin{tabular}{|c|c|}
\hline 1) Caráter científico & São conteúdos com teor científico. \\
\hline 2) Indexadores & $\begin{array}{l}\text { Bases de dados e Diretórios que almejam a } \\
\text { visibilidade do periódico. }\end{array}$ \\
\hline $\begin{array}{l}\text { 3) Gestão editorial (Título, ISSN, Data de } \\
\text { criacão) }\end{array}$ & $\begin{array}{l}\text { Dados importantes que a revista apresenta no } \\
\text { foco escopo na páqina inicial. }\end{array}$ \\
\hline $\begin{array}{l}\text { 4) Estatuto e/ou outro documento sobre a } \\
\text { Institucionalidade }\end{array}$ & Descrição do vinculo Institucional \\
\hline $\begin{array}{l}\text { 5) Descrição dos tipos de documentos e escopo } \\
\text { das pesquisas passíveis de submissão }\end{array}$ & $\begin{array}{l}\text { Diretrizes para autores, a tipologia, o formato e } \\
\text { normas de publicacão }\end{array}$ \\
\hline 6) Descrição do procedimento de avaliação & $\begin{array}{l}\text { Diretrizes para autores em relação a avaliação } \\
\text { do artigo. }\end{array}$ \\
\hline $\begin{array}{l}\text { 7) Estrutura dos textos e normas bibliográficas } \\
\text { adotadas }\end{array}$ & $\begin{array}{l}\text { Apresenta-se nas diretrizes para autores as } \\
\text { devidas informacóes. }\end{array}$ \\
\hline 8) Fluxo editorial & $\begin{array}{l}\text { O processo da avaliação de artigos até a } \\
\text { publicacãa }\end{array}$ \\
\hline $\begin{array}{l}\text { 9) Composição da equipe editorial: Editores- } \\
\text { chefes - filiação institucional e seus currículos } \\
\text { atualizados devem estar on-line (Lattes) }\end{array}$ & Responsáveis pela gestão e fluxo do periódico. \\
\hline $\begin{array}{l}\text { 10) Porcentagem de editores associados ativos } \\
\text { com afiliação estrangeira (mín. } \\
15 \% \text { recomendada: } 25 \% \text { ) - exceto quando o } \\
\text { editor centraliza a função }\end{array}$ & Vinculo com autores, pareceristas estrangeiros \\
\hline $\begin{array}{l}\text { 11) Avaliação de manuscritos: avaliação por um } \\
\text { ou mais editores e pareceristas }\end{array}$ & Processo de avaliação por pares \\
\hline 12) Pontualidade para admissão & O controle do aceito ao artigo (Avaliação) \\
\hline $\begin{array}{l}\text { 13) Idioma dos títulos, resumos, palavras-chave } \\
\text { e texto ênfase no português e inglês }\end{array}$ & Bilíngüe \\
\hline $\begin{array}{l}\text { 14) Porcentagem de artigos originais em inglês- } \\
\text { Linguística, Letras e Artes mín. } 20 \% \\
\text { recomendado } 30 \%\end{array}$ & $\begin{array}{l}\text { Artigos internacionais visam a qualificaro } \\
\text { periódico }\end{array}$ \\
\hline $\begin{array}{lll}\text { 15) Utilizar preferencialmente } & \text { resumos } \\
\text { estruturados }\end{array}$ & Organização das informações do conteúdo \\
\hline $\begin{array}{l}\text { 16) Afiliação de autores: Porcentagem de } \\
\text { autores com afiliação estrangeira Linguística, } \\
\text { Letras e Artes: min.: } 20 \% \text { e recomendável: } 25 \%\end{array}$ & $\begin{array}{l}\text { Manter a flexibilidade de vinculo nacional e } \\
\text { internacional }\end{array}$ \\
\hline
\end{tabular}

Fonte: Scielo, adaptada pelos autores.

As revistas selecionadas foram analisadas, a partir do quadro 3, que corresponde a parte dos critérios SciELO, conforme descrito. A análise dos processos editoriais, como as características que compõem o corpo da revista, e cada uma apresenta uma tipologia diferente, presente ou não, nas 21 revistas.

O quadro 1 apresenta os plugins (Ferramenta de artigo) habilitados no sistema OJS, que são ferramentas que auxiliam na gestão da visibilidade, acessibilidade dos artigos, além de trazer reconhecimento ao periódico. 


\section{ANÁLISE DOS RESULTADOS E DISCUSSÃO}

O presente estudo buscou analisar as revistas de Biblioteconomia e Ciência da Informação e teve como objetivo investigá-las, a partir dos plugins Open Journal System e critérios SciELO.

As revistas apresentam os critérios 1 e 2, que incidem no caráter científico e são indexadas em bases de dados e diretórios, exceto a revista Tendências ${ }^{1}$ da Pesquisa Brasileira em Ciência da Informação, assim como a Brazilian Journal of Information Science, dificultando o acesso para a coleta de dados. Diante disso, o critério 3, que se refere à gestão editorial, mostrou-se uma flexibilidade nas revistas, pois as mesmas trazem dados importantes. Mas, é perceptível a ausência de informações, como o ISSN e a data de criação, o que remete à relevância ao que necessita ser harmônico na íntegra, pois a falta de informações dificulta a visibilidade acerca do conhecimento, que precisa ser fornecido.

Com o decorrer da análise é possível perceber que 18 revistas apresentam informações relacionadas à instituição vinculada, assim atendem o critério 4 , apenas a revista Brazilian Journalism Research (BJR), que não consta nenhum documento tratando do assunto. Já no que se refere ao critério 5, tratam-se das diretrizes que explicam o tipo de documento, o escopo de pesquisa aos artigos que brevemente irão ser submetidos. Observa-se a preponderância das 19 revistas, por conter essas normas a acesso dos autores e usuários.

Assim no como o critério 6 , as diretrizes que descrevem o processo de avaliação estão presentes nas 19 revistas. Nota-se a relevância de manter seus autores e leitores cadastrados informados quanto às políticas, normas e diretrizes que toda revista precisa fornecer e construir um vínculo harmônico entre eles, para ter reconhecimento científico.

A norma de submissão, com a estrutura do artigo, denominada como o critério 7 , mostrou que as revistas de estrato A1 e A2 empregam a norma. Vale dizer, ainda, que o estrato Qualis B1 também possui um número significativo de periódicos, que incidem na norma para criação de artigo, exceto as revistas InCID e Perspectivas em Gestão \& Conhecimento.

\footnotetext{
${ }^{1}$ Revistas Tendências da Pesquisa Brasileira em Ciência da Informação e Brazilian Journal of Information Science não foram analisadas nos instrumentos de pesquisa, em virtude dos link quebrados.
} 
Por sua vez, o critério 8, denominado como o fluxo editorial, se remete ao fluxo a que uma produção científica é designada aos processos até a publicação final na revista. Com esse critério, averiguou-se a ausência da descrição e um documento que houvesse menção do assunto em periódicos de estrato $A 1$ e os demais apresentam de forma sutil.

Diante desse resultado, salienta-se a incoerência na avaliação, o que deixa passar despercebido um dos critérios mais importantes. Porém, existem outros itens no conjunto, com relevância significativa, ou seja, a falta de algum critério não diminui o restante, mas, pensando na comunidade científica o quão é desvantajosa a ausência para contribuição de conhecimento. Além do mais, os outros estratos declaram a avaliação por pares, descrita na integra, lembrando da esperança de subir na avaliação, desde que ocorra declínio do grupo A1.

Os dados referentes ao representante editorial, denominado como critério 9, mostra que todas as revistas compõem esse critério. Isso porque, é importante para a gestão do periódico, com uma estrutura organizada para subir o fluxo editorial e o reconhecimento da revista para atingir mais alvos à submissão. Sendo assim, os editores que têm atualização no seu Lattes só devem crescer, profissionalmente, através de citação, onde influencia as novas submissões.

No critério 10, que aborda as afiliações estrangeiras, criar parcerias com autores e pareceristas agregam muito aos periódicos, principalmente com artigos internacionais. Sendo assim, 18 revistas possuem um vínculo com afiliações estrangeiras, com avaliadores e autores internacionais. Assim como o critério 8, o 11 designa a avaliação de manuscritos às cegas ou em duplas cegas, tendo em vista a semelhança dos critérios. Porém, a diferença consiste na forma de denominar os processos.

As revistas $\mathrm{A} 1$ e a Brazilian Journalism Research (BJR), InCID, Intexto não mencionam o processo de avaliação por pares. Assim como os editores, os pareceristas precisam aceitar os artigos para avaliação, possibilitando edições de conteúdos relevantes. Desse modo, constitui-se o critério 12, em que as revistas fornecem admissão de artigos, conforme sua demanda de edição publicada e outras como Brazilian Journalism Research (BJR), Informação \& sociedade estudos, e Revista Digital de Biblioteconomia e Ciência da Informação não fornecem.

A internacionalização é um dos assuntos comentados na comunidade cientifica, por compor um reconhecimento à estrutura de um artigo a trazer ao leitor a facilidade 
com o seu formato, atribuindo aos artigos as características que agregam valor ao conteúdo. Um dos itens utilizados nas revistas são dois idiomas diferentes, intitulado ao critério 13, inseridos em títulos, resumos e a página da revista. A revista Pesquisa Brasileira em Ciência da Informação e Biblioteconomia e Brazilian Journalism Research $(B J R)$ foram as únicas que não contêm artigos em dois idiomas, mas, assim como as outras revistas, têm uma função de trocar o idioma da página, assim, pensam na diversidade de leitores.

O Critério 14 refere-se aos artigos internacionais em inglês. Através da análise nas edições publicadas, pode-se perceber que as revistas publicam uma porcentagem menor que o recomendável de $30 \%$, o que se leva a entender que a nacionalização é valorizada, e, também, que o idioma, em espanhol, é bastante publicado nas revistas.

A realização da análise permitiu averiguar que a organização do conteúdo, nas 19 das 21 revistas analisadas, é evidente. Tratando-se do critério 15, os resumos, nos metadados, contribuem na disseminação e recuperação e estão presentes nos metadados do sistema OJS das 19 revistas analisadas.

A flexibilidade ao vínculo institucional nacional e internacional finaliza a primeira etapa da análise, como o critério 16, de 13, das 19 revistas. Já a Transinformação, Informação \& Informação, Brazilian Journalism Research (BJR), Ciência da informação, Intexto e Perspectivas em Gestão \& Conhecimento possuem inflexibilidade ao vínculo, pois a porcentagem maior é de vínculo nacional.

\subsection{Análise de Plugins habilitados no 0J S}

A análise iniciou pelo plugin 1, "como citar o artigo", ele permite copiar a referência do trabalho, em diversas normas, ABNT, APA e VANCOUVER e outros. Observa-se, na figura 5 , que 11 revistas não habilitaram o plugin, mas, nas outras 8 revistas constam o plugins ativos. Com base neste resultado, foi possível compreender a ausência dessa ferramenta numa porcentagem maior e que o leitor terá dificuldade na busca da fonte, na íntegra.

O plugin 2, que é exibir metadados, traz informações extras do artigo, como ORCID, afiliação do autor, título e outros. Diante disso, 9 revistas fazem uso, contudo as 10 revistas não têm habilitação e, assim como já foi explicado, duas revistas estão com link quebrados e não fizeram parte nesta análise. Sabe-se da importância de divulgação de periódicos e artigos, e nesse aspecto, é percebível a presença de dificuldade, diante 
da ausência ao conhecimento dessas ferramentas ou por opção da equipe editorial, pois cada uma gerencia da melhor forma de possível.

Os plugins 3 , de enviar artigo via e-mail, permite que o usuário cadastrado envie o artigo para e-mail. O plugin 4, de enviar comentário, possibilita que os usuários ou leitores façam comentários sobre o artigo, que fica junto com artigo. Assim, todos que têm acesso podem ler, ambos são novidades para umas e conhecidos para outras. Nota-se, ainda, na figura 5, que as revistas que contêm eles habilitados, são de estrato B1, pois, das três revistas mais renomadas, duas têm plugins diferentes habilitados.

Diante desses dados, é válido ressaltar as revistas que fazem o uso dessas ferramentas, que são Encontros Bibli; Informação \& Informação com estrato A2; Ágora e as demais são estrato B1, RBBD Revista Brasileira de Biblioteconomia e Documentação; Revista Digital de Biblioteconomia e Ciência da Informação. Um fato curioso é que as revistas de estratificação mais elevadas são inconsistentes na habilitação desses plug-ins. Fica a impressão de que essas ferramentas não são tão relevantes a utilização.

A funcionalidade da ferramenta de imprimir, que corresponde ao plugin 5 , resultou nas 11 revistas que não têm a habilitação desse plugin. Já 8 revistas; fazem a utilização de fornecer a ferramenta de imprimir o artigo. Dessa forma, mostra que os periódicos não são ligados a esse plugin.

O plugin 6, de métrica de acesso, é dos mais utilizados no OJS. Porém, pode-se constatar que, por mais que seja recomendável, a utilização é de responsabilidade dos editores e do comitê editorial decidirem o que é melhor para sua revista.

Constatou-se que, de 21 revistas, 10 não têm a totalidade de plugins habilitados na página na integra, sendo que duas não foram analisadas, por link quebrado. Isso nos faz pensar no motivo da ausência, pois pode ser a falta de conhecimento ao sistema Open Journal System ou, até mesmo, a decisão de não usar, apesar de a abrangência de padronização ser vista, na prática, completamente diferente, por conta da inconsistência na organização de metadados e na conferência para qualificação, sem ênfase.

\section{CONSIDERAÇÕES FINAIS}

A partir da análise das revistas, pode-se dizer que o padrão de qualificação segue, conforme a revista estipula. Entende-se que, a partir da avaliação Qualis, as revistas 
se preocupam com um padrão a ser seguido. O periódico é uma fonte de produção científica, buscar melhorias e alternativas que contribuam na visibilidade, é o recomendável.

Diante da análise, algumas revistas com estratos significativos apresentaram inflexibilidade com resultados não favoráveis, nos quais trazem a reflexão, sobre até que ponto esses critérios influenciam na mudança de estrato, e será que realmente cumpri-los se faz a melhor avaliação? As perguntas surgem e respondê-las não cabe à autora e, sim, entender que o processo é constante de qualificação, a cargo dos editores, antes da avaliação, pois sabemos que, nem sempre, as lacunas vão deixar de existir. Isso porque, as revistas são autônomas nas decisões, e, de certa forma, não cabe estabelecer uma padronização, desde que haja conferência em quantificar e numerar os equívocos que infligem a qualidade da produção Científica.

Porém revistas de estratos B1 vêm alcançando um patamar bastante expressivo, ao atender os critérios e utilizar plugins, por isso acredita-se que, na próxima avaliação, mudanças ocorrerão. Visto que o estrato A1 quer dizer algo bem-sucedido, por meio de diretrizes e critérios presentes na revista, mas, na análise, foi possível averiguar que nem todas as revistas de $\mathrm{Cl}$ fazem uso dos plugins, pois só utilizam o básico do resumo do artigo, o restante não. Portanto, qualquer ausência se faz inexistente. Pensando assim, se não houver uma qualificação estruturada, o que será das revistas? Sabe-se que as mudanças na tecnologia e nos novos métodos vão surgir e, com elas, a esperança que a comunidade científica acredita para a consolidação.

\section{REFERÊNCIAS}

BANDEIRA, Pablo Matias; FREIRE, Isa Maria. Movimento de Acesso Aberto no Brasil: contribuição do Instituto Brasileiro de Informação em Ciência e Tecnologia a partir da implementação do Sistema Eletrônico de Editoração de Revistas. Pesquisa Brasileira em Ciência da Informação e Biblioteconomia, v. 12, n. 1, 2017. Disponível em: http://www.ies.ufpb.br/ojs/index.php/pbcib/article/view/33788/17376. Acesso em 08 jun. 2018. BERTERO, C. O. Caldas, M. P., \& Wood Jr., T. (2005). Introdução: produção científica em administração no Brasil. In C. O. Bertero, M. P. Caldas, \& T. Wood Jr., Produção científica em administração no Brasil: O estado da arte. São Paulo: Atlas.

BOURDIEU, P. Os usos sociais da ciência: por uma sociologia clínica do campo científico. São Paulo: UNESP, 2004. BUENO, W. C. Comunicação científica e divulgação científica: aproximações e rupturas conceituais. Informação \& Informação, v. 15, n. esp., p. 1-12, 2010. COELI, Cláudia Medina; LIMA, Luciana Dias de; CARVALHO, Marilia Sá. Hipercompetitividade e integridade em pesquisa. Cad. Saúde Pública, Rio de Janeiro, v. 34, n. 1, 2018. Disponível em: http://www.scielo.br/scielo. php?script=sci_arttext\&pid=S0102311X2018000100101\&lng=en\&nrm=iso. Acesso em:01 Nov. 2018. 
CAPURRO, R.; HJØRLAND, B. O conceito de informação. Perspectivas em Ciência da Informação. Belo Horizonte: v. 12, n. 1, p. 148-207, jan/abr 2007.

CORRÊA, Tatiane Priscila Pinto; MIRANDA, Angélica Conceição Dias. Critérios de qualidade em revistas científicas de Acesso aberto em educação da região sul do Brasil. REBECIN, v. 3, n. 2, p. 51-66, jul./dez. 2016. Disponível em:

http://abecin.org.br/portalderevistas/index.php/rebecin/article/view/48/p. Acesso em: 18 jun. 2018. CORRÊA, Tatiane Priscila Pinto et al. Usabilidade da seção de avaliação do sistema eletrônico de editoração de revistas através da opinião dos avaliadores do portal de periódicos científicos da FURG. Revista ABC: Biblioteconomia em Santa Catarina, Florianópolis, v. 17, n. 1, p. 217-18, 2012. Disponível em: http://revista.acbsc.org.br/racb/article/view/823/pdf_80. Acesso em:15 maio. 2018. COSTA, M.P.; LEITE, F.C.L. Repositórios institucionais da América Latina e o acesso aberto à informação científica. Brasília: IBICT, 2017.

FACHIN, G R. B. Modelo de avaliação para periódicos científicos on-line: proposta de indicadores bibliográficos e telemáticos. 2002. 210 f. Dissertação (Mestrado em Ciência da Informação) Universidade Federal de Santa Catarina, Florianópolis. Disponível em:

https://repositorio.ufsc.br/handle/123456789/83088. Acesso em: 04 jun. 2018.

GIL, A. C. Como elaborar projetos de pesquisa. São Paulo: Atlas, 2002. 175p.

IBICT, Instituto Brasileiro de Informação Científica e Tecnológica. OJS em uma hora: uma introdução ao Sistema Eletrônico de Editoração de Revistas SEER/OJS versão 2.1.1. Trad. por Ramón Martins Sodoma da Fonseca. Brasília: IBICT, 2006. 144 p. Disponível em: https://pkp.sfu.ca/files/ojs_em_uma_hora.pdf. Acesso em: 06 set. 2018.

MEADOWS, Arthur Jack. A Comunicação Científica. Brasília: Briquet de Lemos, 1999.

MEDEIROS, Jackson da Silva. Abordagem bourdieusiana para uma análise de campo: um enfoque para a comunicação científica e o acesso aberto. Em Questão Porto Alegre. vol. 23, n. 2 (maio/ago. 2017), p. 98-119. Disponível em:

http://www.redalyc.org/pdf/4656/465650858006.pdf. Acesso em: jun. 2018.

MESSIAS, L. C. S. Informação: um estudo exploratório do conceito em periódicos científicos brasileiros da área de Ciência da Informação. UNESP. Marília, 2005. Disponível em:

https://www.marilia.unesp.br/Home/Pos-

Graduacao/Cienciadalnformacao/Dissertacoes/messias_Ics_me_mar.pdf. Acesso em: 13 abril. 2018.

PASCUTTI, Pedro G.Entendendo o Qualis Periódicos CAPES. ABEC - Campinas, 2016.

Disponível em:

https://www.abecbrasil.org.br/eventos/xxivcurso/palestras/quarta/pedrogpascutti.pdf. Acesso em: 16 jun. 2018.

PIMENTA, Ricardo. Os novos espaços de comunicação e memória. Ensaio, 2016. Disponível em: http://www.memoriaesociedade.ibict.br/tag/comunicacao-cientifica/. Acesso em: 20 out. 2018.

PINHEIRO, Lena Vania Ribeiro; BRASCHER, Marisa; BURNIER, Sonia. Ciência da Informação: 32 anos (1972-2004) no caminho da história e horizontes de um periódico científico brasileiro.

Ciência da Informação, v. 34, n. 3, 2005. Disponível em:

http://revista.ibict.br/ciinf/article/view/1084. Acesso em: 14 jun. 2018.

PRODANOV, Cleber Cristiano; FREITAS, Ernani Cesar de. Metodologia do Trabalho Científico: Métodos e Técnicas da Pesquisa e do Trabalho Acadêmico. 2. ed. Novo Hamburgo: Associação Pró-Ensino Superior em Novo Hamburgo; Universidade Feevale, 2013. Disponível em: http://www.faatensino.com.br/wpcontent/uploads/2014/11/2.1-E-book-Metodologia-. Acesso: 12 maio. 2018.

PKP PUBLIC KNOWLEDGE PROJECT. Open Journal Sytem. 2008. Disponível em: http://pkp.sfu.ca/ojs. Acesso em: 10 Ago.2018. 
SARACEVIC, Tefko. Tecnologia da informação, sistemas de informação e informação como utilidade pública. Ciência da Informação, [S.I.], v. 3, n. 1, june 1974. Disponível em: http://revista.ibict.br/ciinf/article/view/41/41. Acesso em: 12 maio. 2018.

TARGINO, Maria das Graças; TORRES, Názia Holanda. Comunicação Científica Além da Ciência. Ação Midiática - Estudos em Comunicação, Sociedade e Cultura., [S.I.], jul. 2014. ISSN 2238-0701. Disponível em: https://revistas.ufpr.br/acaomidiatica/article/view/36899/22924. Acesso em: 17 jun. 2018.

ZAGO, Marco Antonio. Perfil da produção científica no Brasil.(Slide). Disponível em: http://www.fapesp.br/eventos/2011/06/Marco_Antonio.pdf. Acesso em: 18 de jun. 2018. 